\title{
INDUCED OXIDATIVE STRESS BY DEFEROXAMINE (DESFERAL) DURING THE PREGNANCY: PRE AND POST-NATAL DEVELOPMENTAL STUDY
}

\author{
Abeer E. Thanoon \\ Ali S. Alchalabi \\ Department of Physiology, Biochemistry \& Pharmacology \\ College of Veterinary Medicine, University of Mosul, Mosul, Iraq \\ Email:alchalabi@uomosul.edu.iq
}

\begin{abstract}
The aim of the study is to evaluate the effect of induced oxidative stress by the deferoxamine (desferal) during the pregnancy on pre and post-natal developmen. One hundred twenty adult female albino rats, 3 months old, with an average weight of $175-200 \mathrm{~g}$, were randomly distributed into two main groups (60 rats/group). The $1 \mathrm{st}$ (control group) was injected with $0.3 \mathrm{ml}$ physiological salt solution / animal, and the 2nd group was injected with $100 \mathrm{mg}$ deferral $/ \mathrm{kg} \mathrm{B.W.} \mathrm{which} \mathrm{was} \mathrm{given}$ intraperitoneal once daily for three consecutive weeks (during the pregnancy period). At the end of the treatment, each group in turn was divided into two parts, each section comprising 10 animals, blood samples were collected for biochemical analysis, then uterine and fetal tissues collected to observation the studied parameters. Results showed decrease in the numbers of implantation and blastocysts. The number of alive embryos were significantly reduced with an increasing number of dead and reabsorbed embryos, malformation of fetus increase in uterine of the stressed female group compared with control group. Postnatal observations showed significant variations in postnatal development parameters. Our study suggests that the deferral injection has a pro-oxidant capacity on rats' model at dose of $100 \mathrm{mg} / \mathrm{kg}$, and the oxidative stress plays an important role during pregnancy especially on prenatal development as well as persist up to postnatal life.

Keywords: Deferral, Oxidative Stress, Pre and Postnatal Developments.
\end{abstract}

Received: 15 / 12 /2020, Accepted: 24 / 2 /2021.

\section{INTRODUCTION}

Oxidative stress occurs naturally in the body because of an imbalance between oxidants and antioxidants, and it has a vital and effective role in many metabolic processes necessary for the growth and development of various body systems as well as its physiological role in many body functions (Agarwal et al., 2005). Although reactive oxygen species (ROS) are necessary to maintain fetal development, overproduction of the ROS during embryonic life has a detrimental effect due to their interaction with different important cellular processes (Amin et al., 2014). The ROS attack large cellular molecules, and cell structures such as the mitochondria membrane and the endoplasmic reticulum causing oxidative damage leading to changes in the cellular activity through their effect on gene regulatory action on many cellular proteins (He et al., 2017). Most of the biological processes in the uterine The ROS regulate many of the transcription pathway by direct interaction with proteins tissue and ovarian are naturally involved free radicals that act as secondary messengers to perform their cellular response (Torres-Osorio et al., 2019). 
and modification of transcription factors and gene expression (Allen and Tresini, 2000). During pregnancy, an increase of stress severity may lead to unwanted

Pregnancy outcome for instance spontaneous abortion, recurrent pregnancy loss, birth defects, pre-eclampsia, intrauterine growth restriction, minor congenital anomalies, and future diseases in adulthood (Pereira and Martel, 2014; Duhig et al., 2016). It was found that there is a strong link between increased ROS and early pregnancy loss (Bertout et al., 2004). In another study conducted on mice, defects in the mitochondrial respiratory chain resulted in impaired fertility and increased miscarriage rate due to increased oxidative stress (Takamasa et al., 2014). Hubel (1999) found that oxidative stress causes impairment the blood vessels in the placenta leading to decreased oxygen supply, causing abnormal differentiation of the Trophoblast. In addition to that, Min et al. (2009) recorded decreased blood flow in the placenta and damage to fetal tissue due to intrauterine stress. The placenta considered as a rich source of oxidants and antioxidants due to an increase in metabolic efficiency in the placental mitochondria (Agarwal et al., 2012). The formation of an abnormal placenta causes damage to the syncytiotrophoblast that is sensitive to stress during the first trimester of pregnancy, this contributes to recurrent pregnancy loss (Agarwal et al., 2012).

Desferal (deferoxamine mesylate) is an iron-chelating agent used to treat iron overload caused by blood transfusions in adults and children at least 3 years old (Brittenham, 2011). Desferal can lead to increase oxidative stress via activation of free radical production signaling pathway (Francisco et al., 2010). In this research work, our aims are to prove that desferal has pro-oxidant activity during pregnancy and to figure out its effect on pre and postnatal life in rats' model.

\section{Animals}

\section{MATERIALS AND METHODS}

The study was conducted in the Laboratory of the Physiology, Biochemistry and Pharmacology department / Faculty of Veterinary Medicine, University of Mosul. One hundred twenty adult females albino rats at 3 months of age were used, with an average weight of $175-200 \mathrm{~g}$. They were distributed randomly into two main groups, which are control and treatment by 60 rats / group according to the design of the experiment. The laboratory animals were placed in plastic cages for breeding for a period of two weeks, and for environment acclimatization and observing the health status of the rats. The diseased animals were excluded and replaced with healthy rats. The laboratory animals were placed under appropriate environmental conditions in terms of temperature $\left(24 \pm 1{ }^{\circ} \mathrm{C}\right)$, humidity $(60 \pm 10 \%)$, ventilation and adequate lighting, and water and feed were provided to them freely throughout the experiment period (3 weeks).

\section{Experiment of induced oxidative stress}

For inducing oxidative stress, 10 adult females were used in this experiment, were injected with desferal a dose of $100 \mathrm{mg} / \mathrm{ml} / \mathrm{kg} \mathrm{BW}$, i.p once daily for three consecutive weeks. Blood samples were collected one day before the injection of desferal, and after the completion of the injection period for measuring the level of each of MDA and glutathione as evidence of induced oxidative stress. The prescribed dose of desferal was adopted after confirming the occurrence of oxidative stress. 


\section{Experimental design}

The experimental animals were distributed into two equal groups: the control group, which included 60 adult females, were injected with a physiological salt solution of $0.3 \mathrm{ml} /$ animal, and the treatment group that was injected with desferal (deferoxamine methane, NOVARTIS-Switzerland), it was given intraperitoneal once daily for three consecutive weeks throughout the pregnancy period. The day one of pregnancy was determined by viewing the vaginal plug, as well as the presence of sperm in the vaginal swab (Palmer and Post, 1995). Each group was distributed into three subgroups:

1. Treatment group from day 1-7 of pregnancy (20 animals / subgroup).

2. Treatment group from day 1-14 of pregnancy (20 animals / subgroup).

3. Treatment group from day 1-20 of pregnancy (20 animals / subgroup).

At the end of each trial, the rats were distributed into 2 parts; part 1 were sacrificed for biochemical analysis and prenatal life assessment. While, part 2 of each subgroup were left until parturient for assessing postnatal development.

Blood samples were collected from the orbital eye using capillary tube (Van Herck et al., 1998). Uterine samples collection were involved to investigate the prenatal development, In addition to use these samples for assessing oxidative stress biomarkers in both rat dams and their fetuses.

\section{Biochemical analysis}

MDA was measured as a bio marker of lipid oxidation in serum and tissue samples, according to the (Buege and Aust, 1978), where the measurement was based on the interaction between MDA with thiobarbituric acid (TBA), a component of the MDA-TBA2 complex, which absorbs in the wave length of $532 \mathrm{~nm}$.

The concentration of glutathione was determined by the modified Almann method (James et al., 1982). The basis for the estimation of glutathione depends on the interaction between the detector DTNB reagent with glutathione in the sample. The golden yellow color and the intensity of the color depends on the concentration of glutathione. This color is measured using a spectrophotometer at a wavelength of $412 \mathrm{~nm}$.

\section{Pre and postnatal development assessment}

The number of implantation sites, the number of blastocysts in the first week of pregnancy, the number of live and dead embryos, and the number of absorbed embryos in the second week of pregnancy were used to assess the prenatal developments. In addition to that during the third week of pregnancy, the data of the fetuses were recorded in terms of their total number, live, dead and deformed number.

For postnatal development females of part 2 were left until delivery. The data were collected immediately after 24 hours of birth. Total number of birth, number, live births, death and a number of anomalies were involved. Weekly body weight gain was measured in pups from 24 hours after delivery, D7, D14, D21, and D28 individually. Pups were randomly chosen for studying the postnatal growth rate. The litter size was checked after 24 hours of birth up to 28 days for the following parameters; days for ears, hair and teeth appearance, eye-opening and weaning days were recorded as an indicator for normal growth parameters. 


\section{Statistical analysis}

All data were expressed as mean \pm S.E, independent t-test was employed for determining the significant between pre and post induction of oxidative stress. Whereas, paired t-test was employed for determining the significant between studied groups by using SPSS program (Allen et al., 2014). $P$-value 0.05 was considered significant.

\section{Experiment of oxidative stress induction.}

\section{Effect of desferal injection on glutathione level.}

The injection of $100 \mathrm{mg}$ desferal $/ \mathrm{kg}$ body weight led to significant decline in serum glutathion level after 14 and 20 days of injection between pre and post injection at P-value 0.001, 0.002 respectively. Whereas, injection of DFO up to 7 days showed non significant decline in glutting at $\mathrm{P}$-value 0.055. (Figure 1).

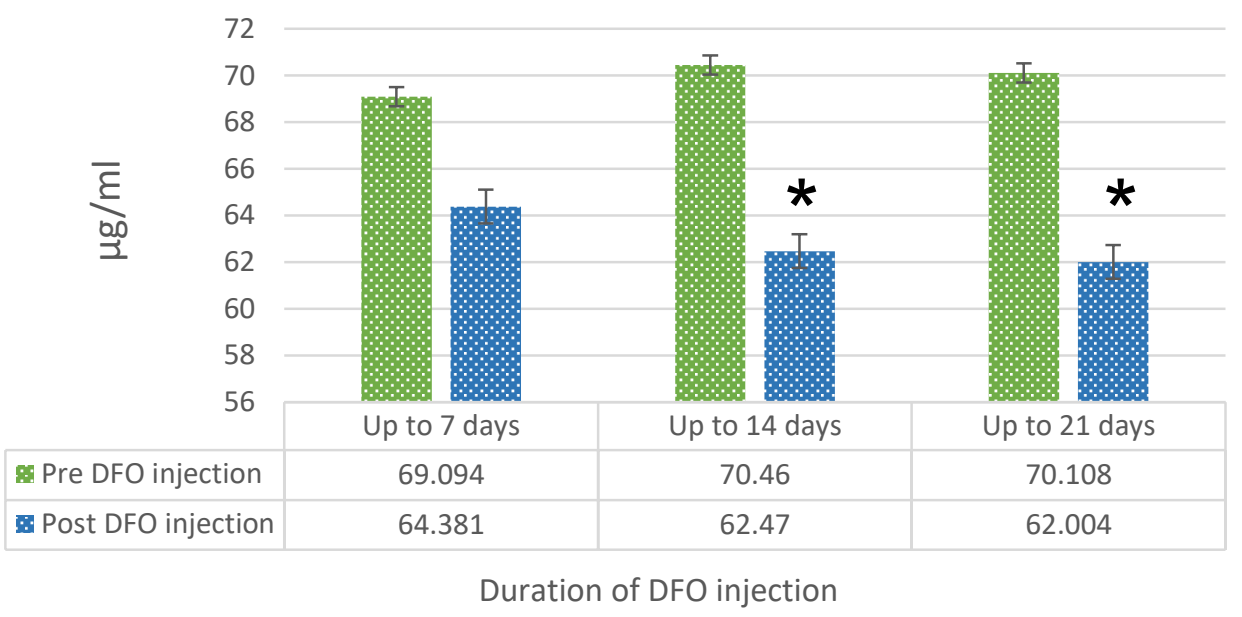

Figure (1): Effect of desferal injection on serum glutathione.

\section{Effect of desferal injection on lipid peroxidation marker.}

Lipid peroxidation marker (MDA) was significantly higher in post injection duration compare to pre injection period after 14 and 20 days of continuous desferal injection to induce oxidative stress at P-value $0.001,0.004$ respectively. In the time, the first 7 continuous days had no significant elevation in lipid peroxidation level at P-value 0.064. (Figure 2). 


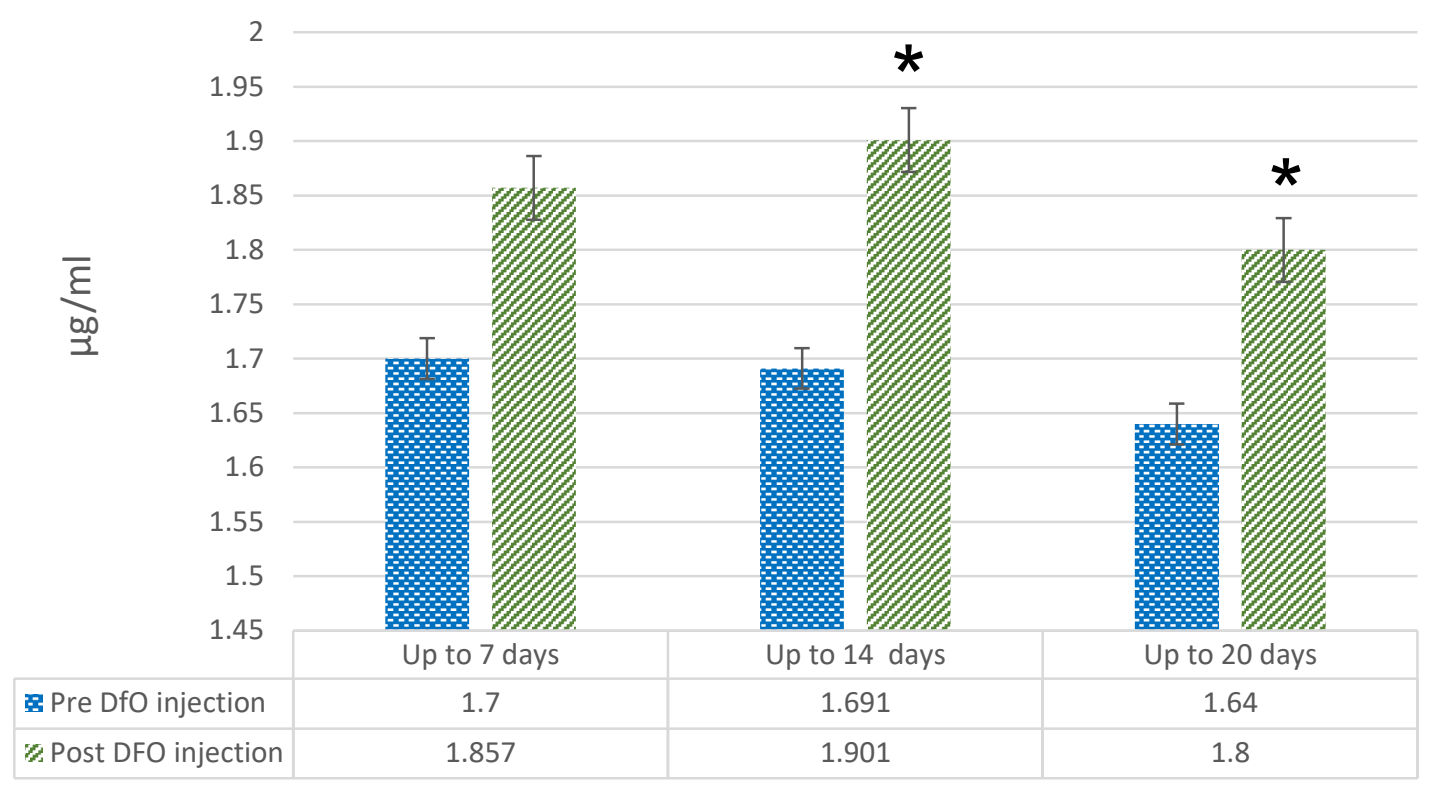

Duration of DFO injection

Figure (2): Effect of deferral injection on serum lipid peroxidation .

\section{Experiment of effect of induced oxidative stress in both pregnant rats and their} fetuses.

Effect of induced oxidative stress on glutathione level after 7, 14 and 20 days of pregnancy.

The statistical analysis showed no significant differences for the glutathione level in serum and uterine tissue after injecting female rats with desferal for 7 days at significant level the 0.064 and 0.18 for both serum and uterine tissue, respectively. (Figure 3).

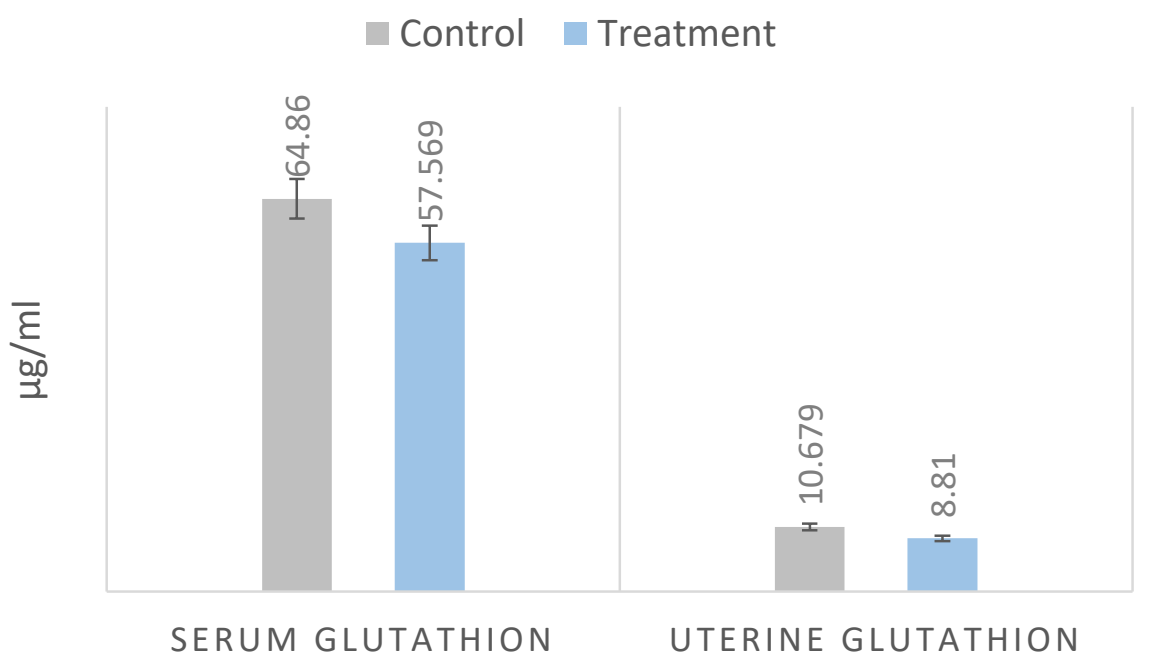

Figure (3): Effect of oxidative stress on both serum and uterine tissue glutathione level after 7-days of pregnancy. 
The induced oxidative stress showed significant changes represented by a decrease in the glutathione level in serum and embryonic tissues at the $P$-value was 0.032 and 0.001 , respectively. (Figure 4)

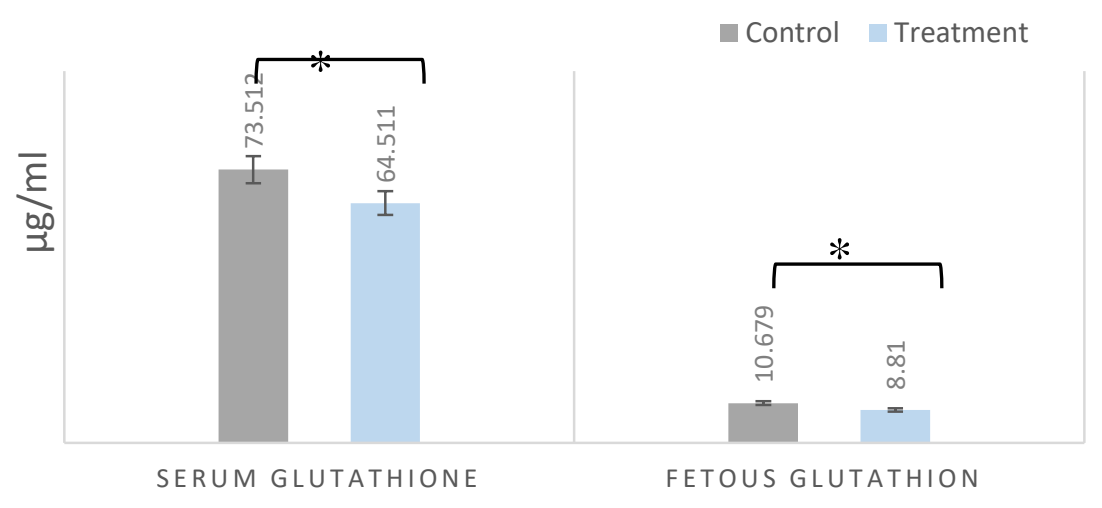

Figure (4): Effect of induced oxidative stress on both serum and uterine tissue glutathione level after 14-days of pregnancy.

Whereas, glutathione level in both pregnant rats and their fetuses after 20 days of injection with desferal led to a significant decrease in the serum glutathione level at P-value was 0.006 and 0.042 , respectively. (Figure 5)

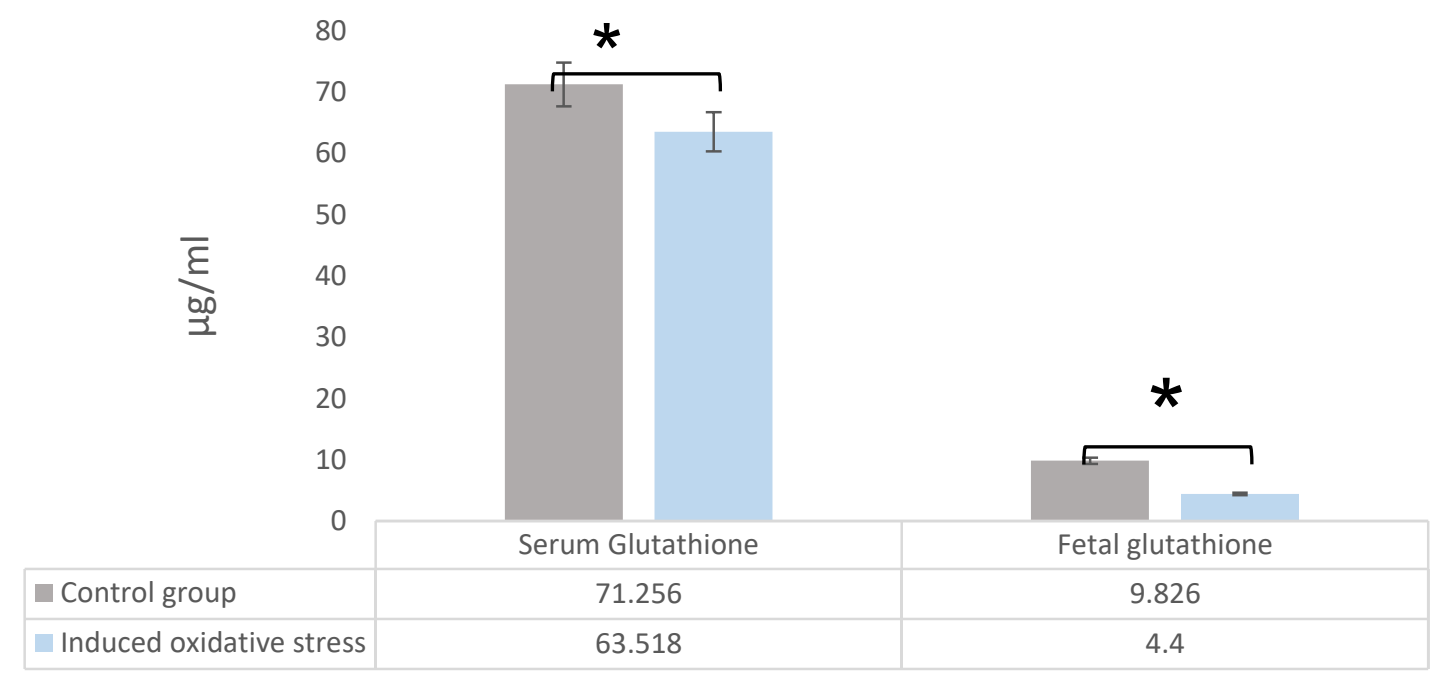

Figure (5): Effect of induced oxidative stress on both serum and uterine tissue glutathione level after 20-days of pregnancy.

Effect of induced oxidative stress on MDA level after 7, 14 and 20 days of pregnancy.

The induced oxidative stress by desferal did not showed non-significant elevation in the MDA level of both serum and uterine tissue after ip injection for 7 days at the $P$-value was $0.076,0.085$ for both serum and uterus respectively. (Figure $6)$. 


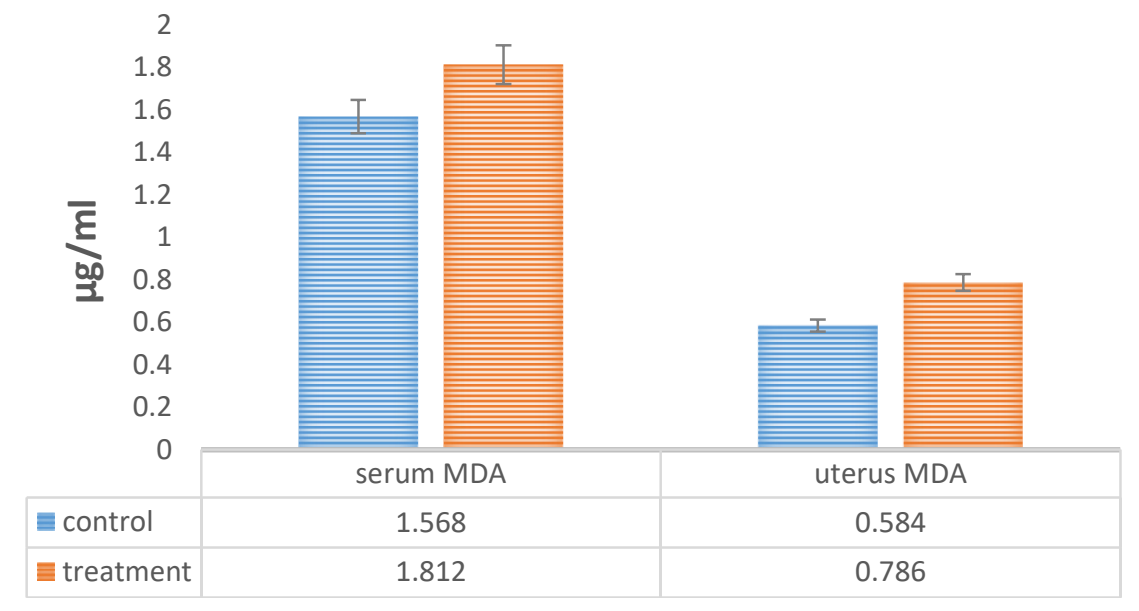

Figure (6): Effect of induced oxidative stress on both serum and uterine tissue MDA level after 7-days of pregnancy.

The MDA level in the serum of pregnant rats showed a significant increase compared to the control group at the level $P$-value 0.032 , While, the mean value level of MDA of belongs to induced oxidative stress group was not significant compared to the its value of the control group P 0.084. (Figure 7)

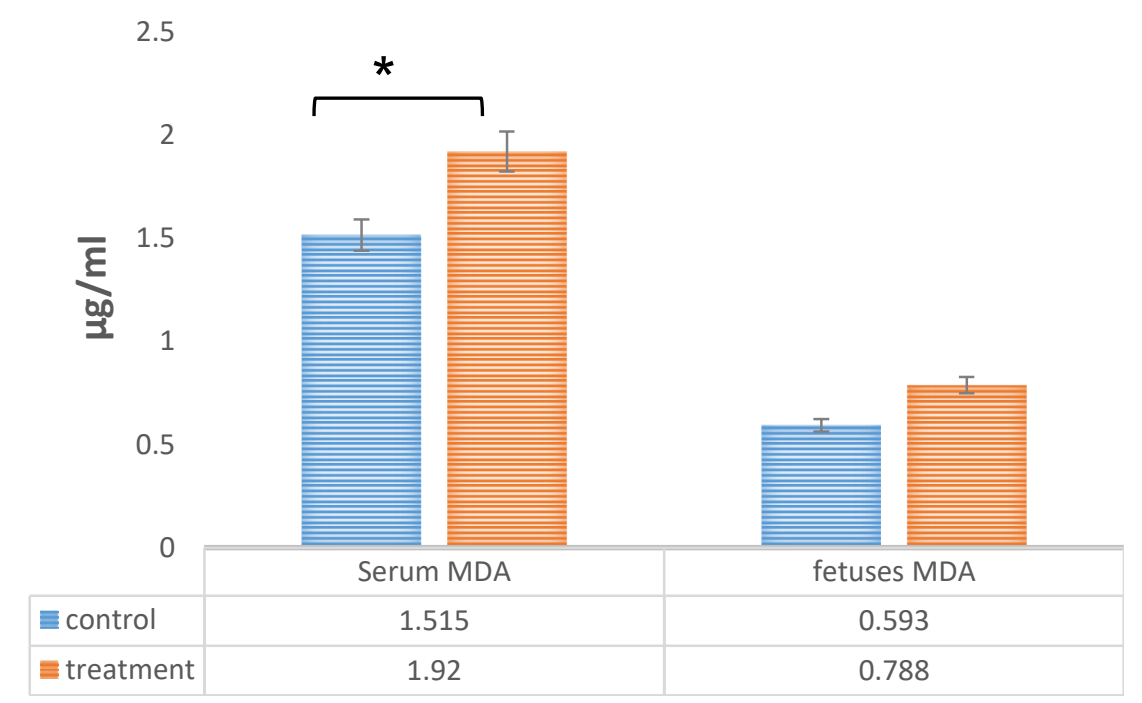

Figure (7): Effect of induced oxidative stress on both serum and fetus MDA level after 14-days of pregnancy.

Induced oxidative stress up to 20 days during pregnancy showed a significant increase in the MDA level in serum and fetal tissues between studied groups at the $P$-value was 0.006 and 0.001 , respectively. (Figure 8 ). 


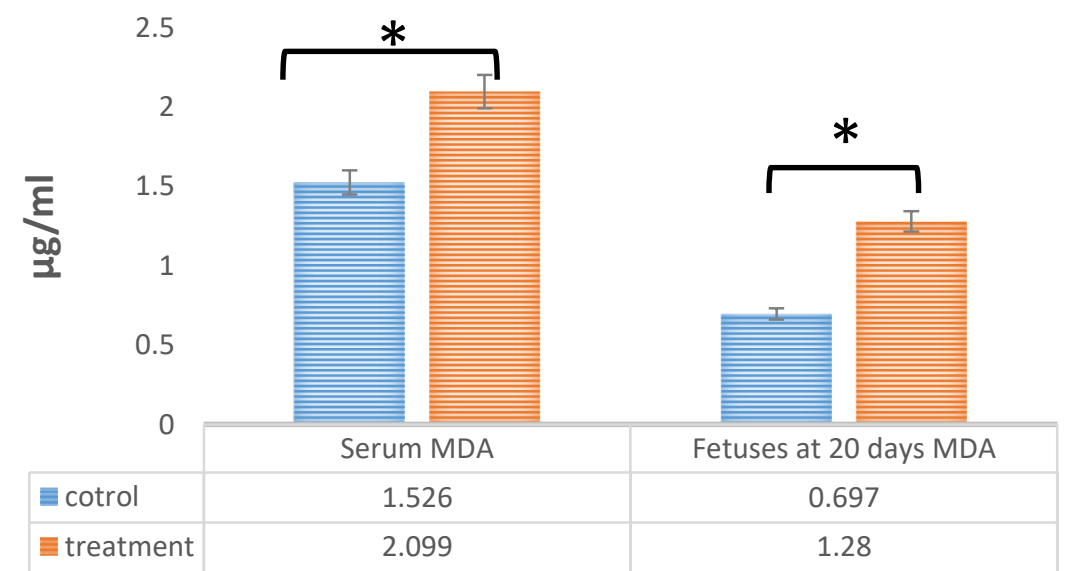

Figure (8): Effect of induced oxidative stress on both serum and fetus MDA level after 20-days of pregnancy.

\section{Experiment of the effect of induced oxidative stress on prenatal development and weight of fetuses at day 20 of pregnancy.}

The statistical analysis of the fetal development data of studied females' rats showed a non-significant decrease in the number of implantations (P 0.104) between control and stressed females. Whereas, the oxidative stress led to a significant decrease (P 0.043) in the average number of blastocysts in the uterus of the stressed females compared with the control females. (Figure 9).

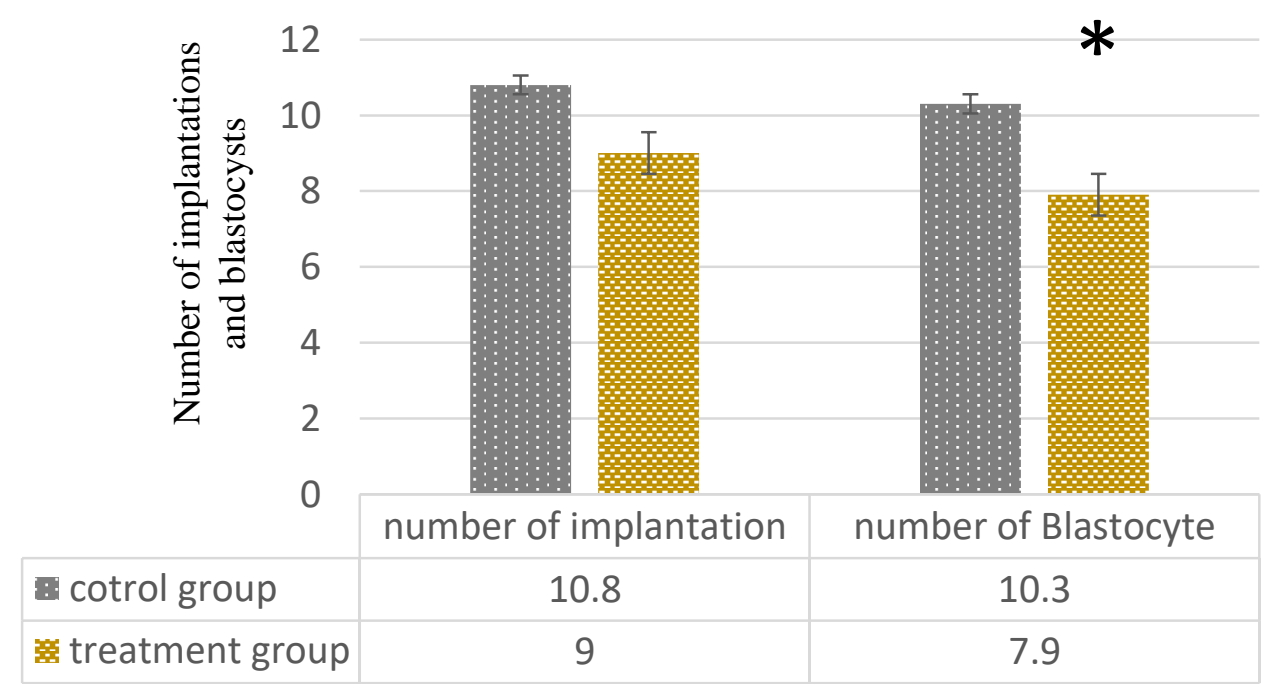

Figure (9): Effect of induced oxidative stress on embryonic development during the first 7 days of pregnancy.

The induced oxidative stress showed no significant decrease in both the total number of embryos and the number of alive embryos of stressed females compared to control females (P 0.105 and 0.051 , respectively). Whereas, the induced oxidative stress resulted in a significant increase in the number of dead embryos and the number of absorbed embryos in the stressed females compared with the control females (P 0.037, 0.001). (Figure 10). 


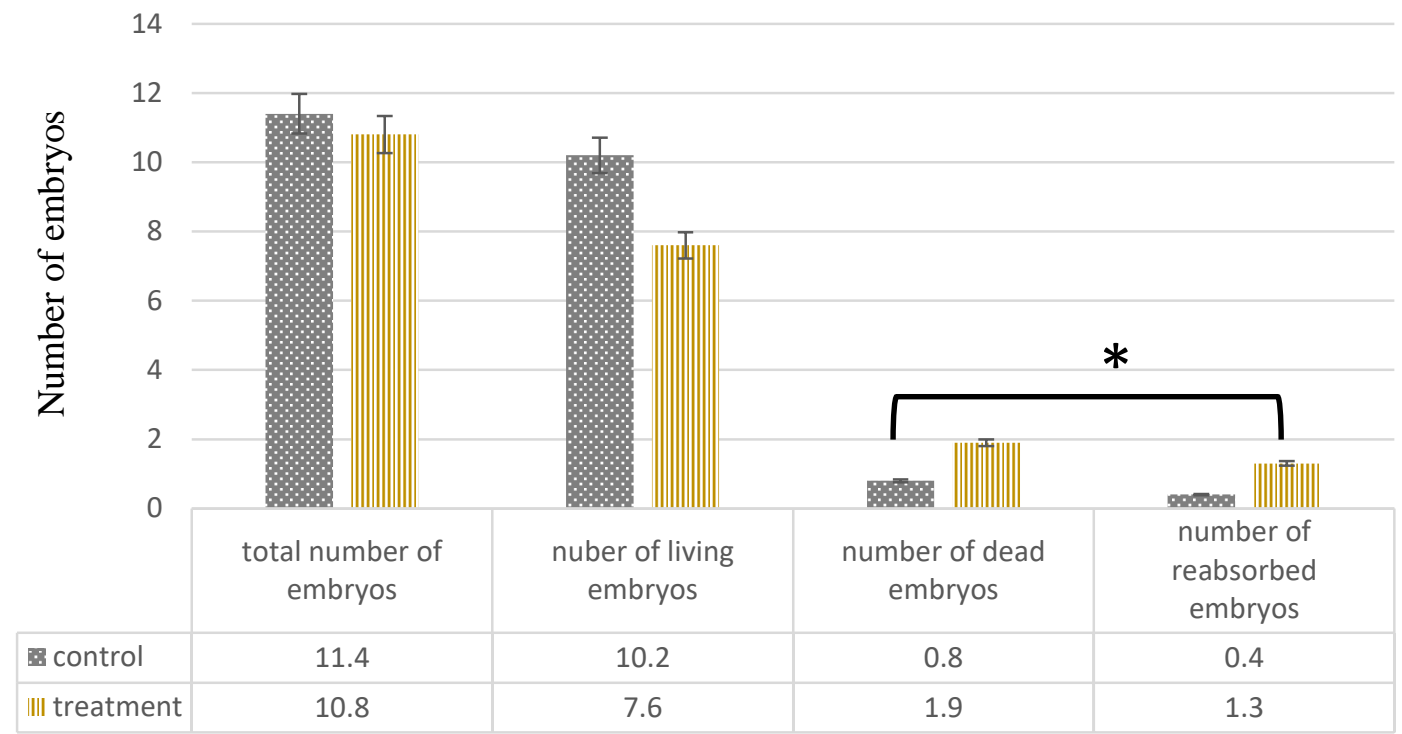

Figure (10): Effect of induced oxidative stress on fetal development after 14 days of pregnancy.

The induced oxidative stress in female rats led to a significant decrease in the total number of adult fetuses and the number of alive fetuses / female compared with the control group females (P 0.001). Whereas, the rate of the number of dead fetuses and the rate of the number of fetal anomalies / female showed a non-significant increase of the intrauterine stressed fetuses compared with the non-stressed fetuses (P $0.813,0.264$, respectively). The weight of the fetuses at day 20 of pregnancy did not show difference between the intrauterine stressed fetuses and non-stressed fetuses (P 0.061). (Figure 11 and 12).

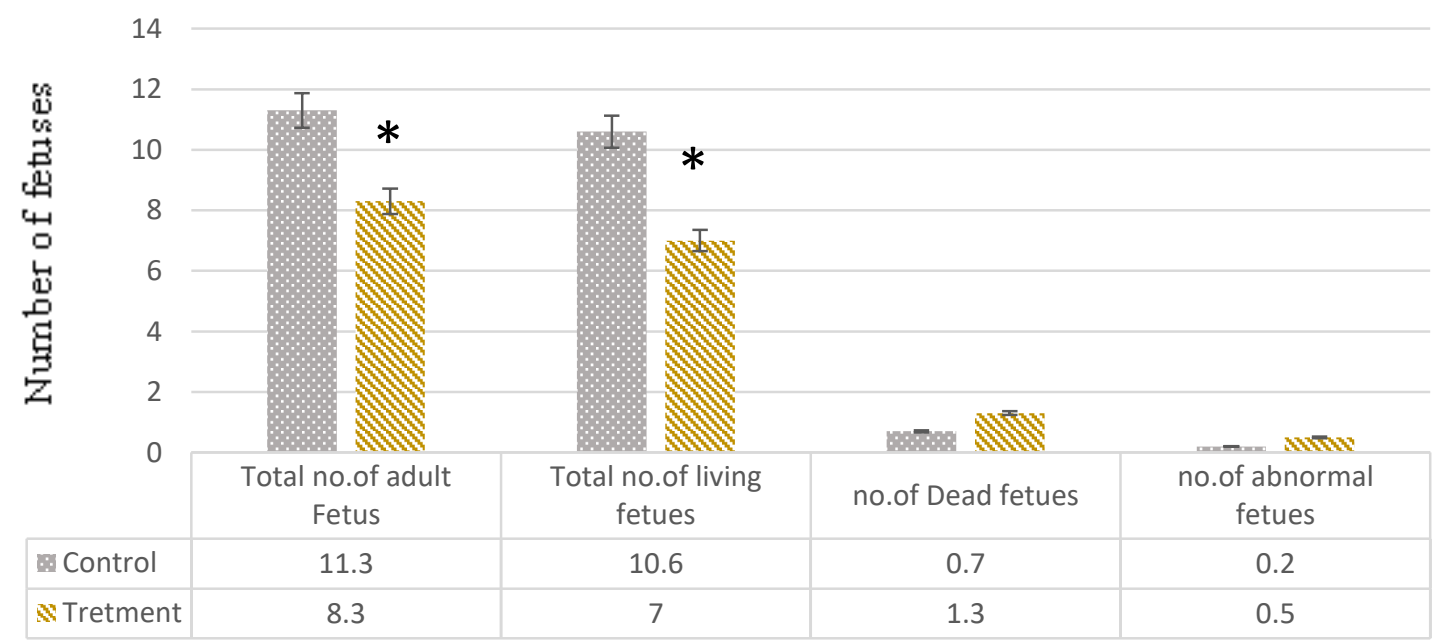

Figure (11): The effect of induced oxidative stress on fetal development after 20 days of pregnancy. 


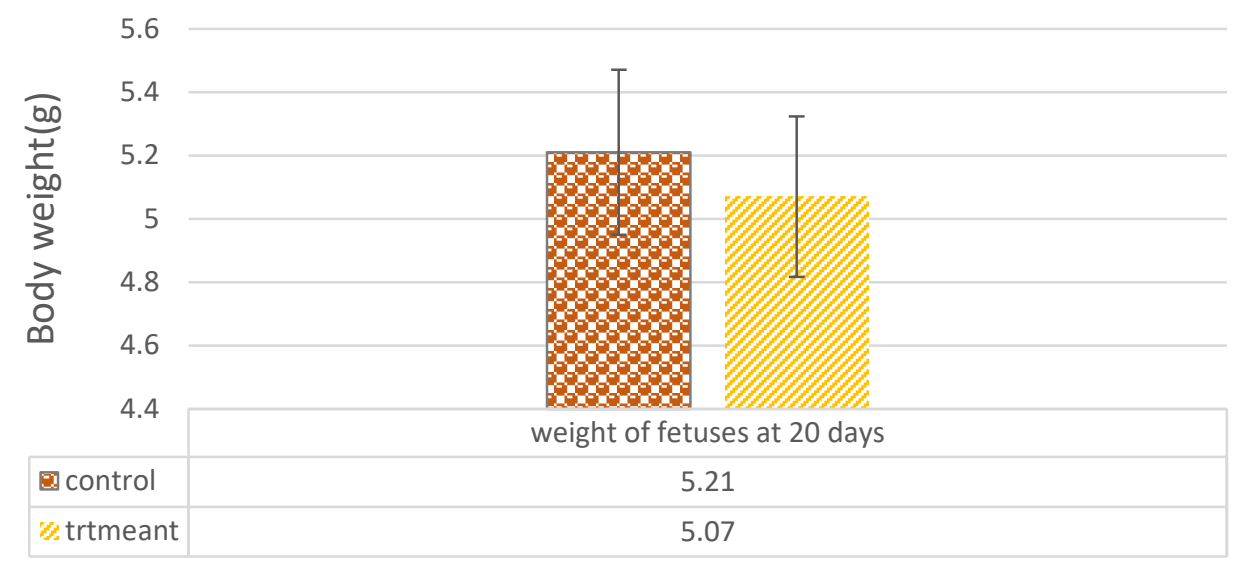

Figure (12): Effect of induced oxidative stress on fetuses' body weight at day20 of pregnancy.

\section{Experiment of the effect of induced oxidative stress on certain postnatal development parameters and weaning day.}

The postnatal development of the newborns of stress subjected rats during a period of 7 and 14 days of pregnancy showed a difference between the two studied groups of some studied criteria. For instance, there was a significant increase in the number of days required for the appearance of hair and teeth in the newborns from the stresses dams compared with the newborns from the normal dams (P 0.004 and 0.001 respectively). While, the other criteria did not show any significant differences between the two groups. (Figures 13 and 14).

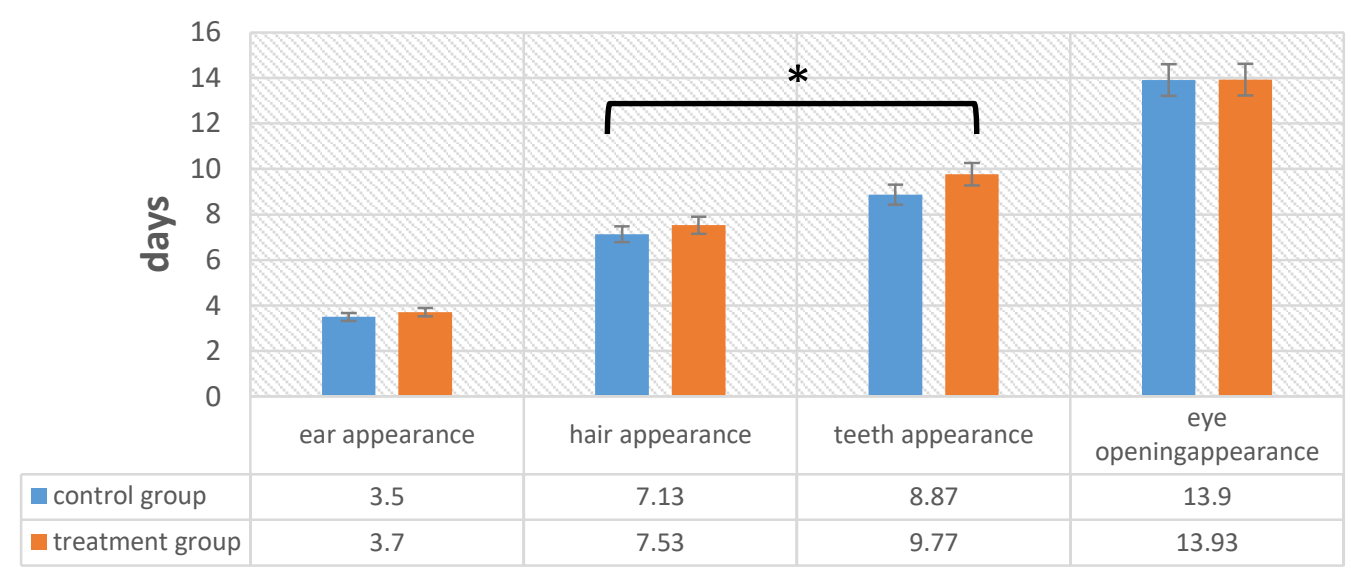

Figure (13): The effect of induced oxidative stress on postnatal development parameters of the experimental female infants during the first week of pregnancy. 


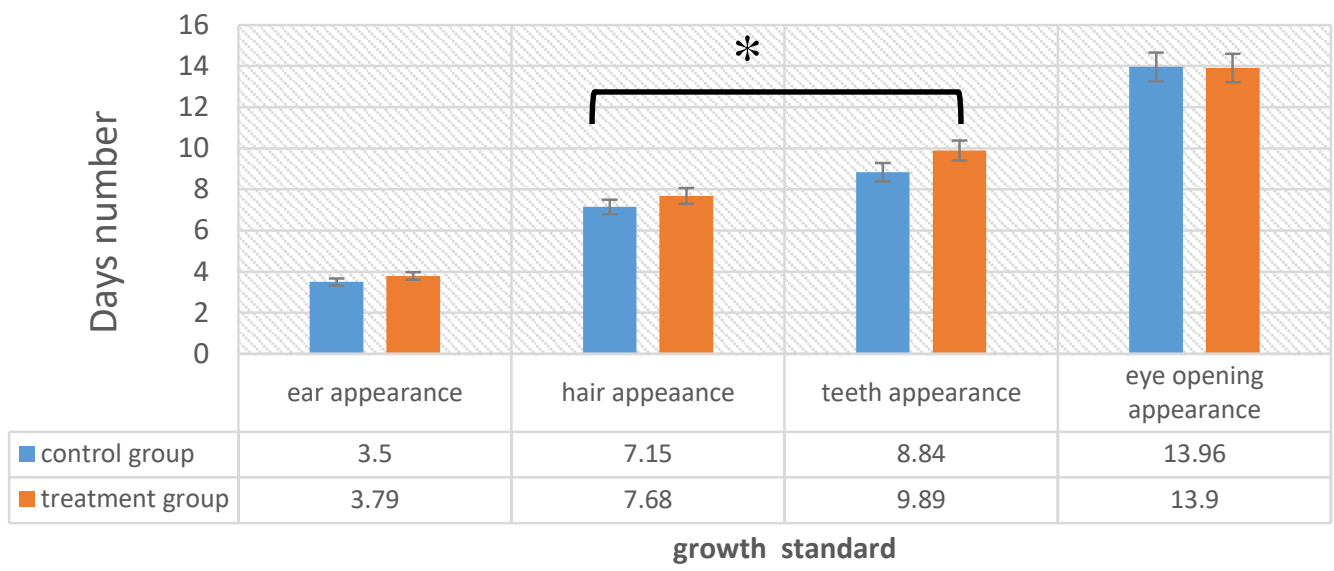

Figure (14): The effect of induced oxidative stress on postnatal development parameters of intrauterine stress subjected pups during the second week of pregnancy.

While, the induced oxidative stress up to 20 days of pregnancy lead to clear changes in some of the studied growth parameters. For instance, the appearance of hair, teeth and the appearance of the eye opening was delayed in the pups of mothers subjected to intrauterine stress up to 20 days compared with the same criteria for the pups of dams of the control group (P 0.045, 0.006, 0.03, respectively). (Figure 15).

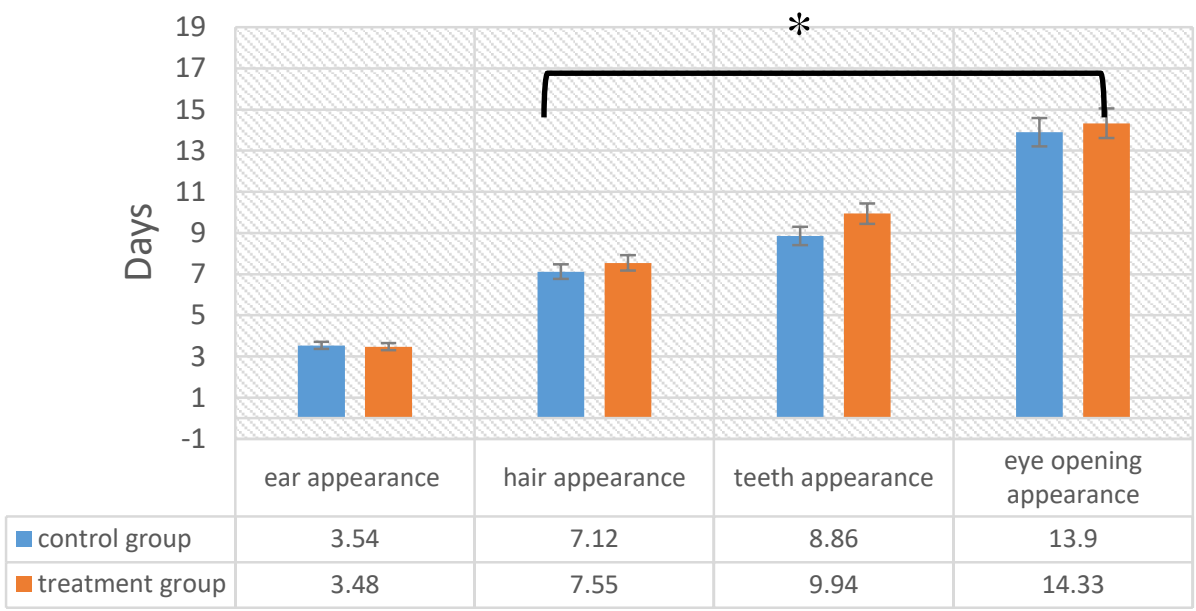

Figure (15): The effect of induced oxidative stress on postnatal development parameters of intrauterine stress subjected pups during the third week of pregnancy.

Statistical analysis using independent t-test for evaluating the data of the weaning age of the pups from both stressed and non-stressed dams resulted in a significant increase in the number of weaning days required for weaning in the intrauterine stressed pups group compared with the control group (P 0.001) (Figure 16). 


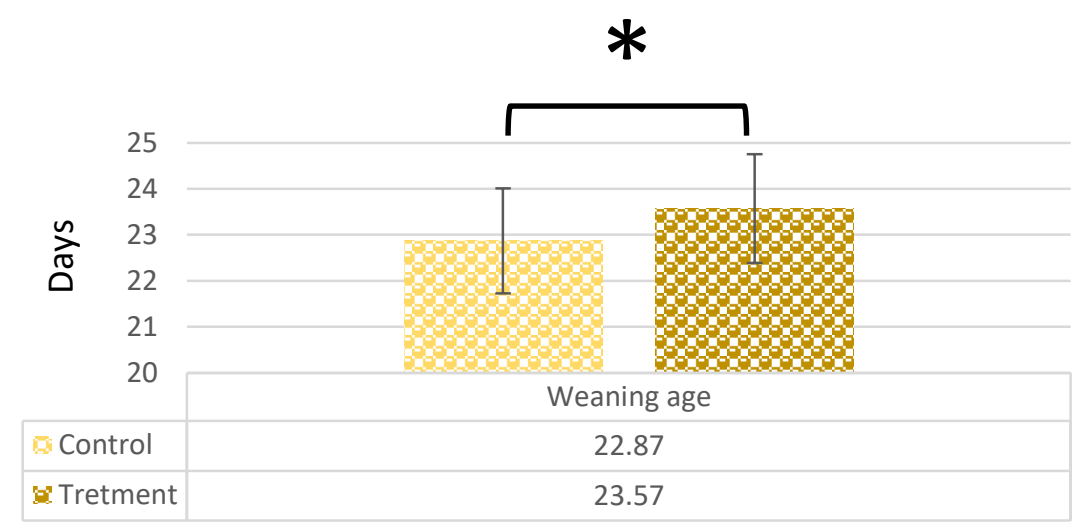

Figure (16): The effect of induced oxidative stress on the weaning age of the experimented pups.

\section{DISCUSSION}

Excessive oxidative stress as a result of an increase in the level of free radicals, especially ROS and hydroxyl, and a decrease in the activity and efficiency of antioxidants within the uterine tissue and the placenta. This gives an important explanation for many cases of pregnancy failure and defects in the growth and development of fetuses during and after pregnancy in a certain period (Silveira et al., 2018; Wu et al., 2017).

For the purpose of inducing oxidative stress in rats, Desferal was used in a high dose for two consecutive weeks. Injecting intraperitoneal resulted in oxidative stress induced through apparent changes in the levels of oxidative markers. desferal works to oxidize iron in cytosol and convert it from the $\mathrm{Fe}^{+2}$ to the $\mathrm{Fe}^{+3}$ by reacting with hydrogen peroxide because of the generation of free hydroxyl radicals in the cell. This indicates that Desferal, in addition to its role as an antioxidant, acts as a prooxidant when used in a high dose for a long time. The stimulation of the lipid peroxidation process resulted from Desferal may be with the presence or absence of iron through the production of highly reactive hydroxyl radicals that are toxic to cells, and this opinion is identical to what was reported by Mukosera et al. (2020); Tada et al. (2015 ); Kim et al. (2007); Poot et al. (1989); Morehouse et al. (1988) ; Morehouse et al. (1987).

The current results are in agreement with a previous study in which researchers demonstrated that $6 \mathrm{mmol}$ of desferal when incubated for 2 hours with erythrocytes led to oxidative stress events by reducing the redox potential of NAD in erythrocytes (Niihara et al.,2002). The other cause of the oxidative stress induced by desferal may be attributed to its role as an electron transport medium from ascorbic acid in cells to oxygen to produce the superoxide anion, which in turn leads to the production of the active nitroxide radicals, as well as the role of desferal in the Fenton reaction (Jiang et al., 2016).

The current study resulted in clear changes in the levels of oxidative stress parameters for pregnant rats and their fetuses at different stages of pregnancy. This was evident in the second week of pregnancy and continued until the end of the trial 
period in both mothers and their fetuses at the level of blood and tissue. The reason for this is due to the insufficiency of the action or the low level of antioxidants, for example glutathione peroxidase, as well as the overproduction of free radicals of various kinds. Where, glutathione is a strong and effective reducing substance in the cell and has a distinct role in the regeneration and maintenance of moderate levels of the enzyme glutathione reductase very important in vital tissues and developing, including the pregnant uterus (Wickens, et al., 1981; Yu, 1994). The current results showed an increase in the level of malondialdehyde and a decrease in the level of glutathione peroxidase, which is due to an increase in the level of free radicals and a decrease in the level of glutathione in the tissue and blood, and this corresponds to previous studies that illustrate the role of oxidative stress in pregnancy (Lu, et al., 2018; Al-Gubory et al., 2010; Patil et al., 2007). Tissue glutathione depletion directly affects the level of antioxidants, making cells more vulnerable to oxidative stress even under physiological conditions (Sekhon et al., 2010) .this mechanism is attributed to a series of interconnected enzymatic processes associated with cellular oxidative stress, which may result in cell death or failure in its basic function. Among these enzymatic processes is the stimulation of arachidonic acid by activating the enzyme phospholipase A2 associated with the release of arachidonic acid, which works to destroy cells that have depleted glutathione because of metabolism (Balsinde et al., 2002). Arachidonic induction by the action of the enzyme lipoxygenase, which in turn stimulates the synthesis of the active superoxide radicals during the metabolism of arachidonic acid, which plays a dangerous toxic role as a result of depletion of glutathione leading to cell damage and death (Mytilineou et al., 2002).

This cellular pathway is one of the most important pathways associated with glutathione depletion, which induces a series of cellular events that end with an increase in the level of free radicals and their attack on cellular molecules, causing sufficient oxidative damage to cell death or loss of its basic function (Katsuki et al., 1995). The increase in malondialdehyde in the body is an important indicator of the severity of the activity of the free radicals produced and their effect on the lipid peroxidation resulted from the occurrence of oxidative stress (Ruder et al. 2009). The active aldehydes are the second messengers of the deleterious activity of the active oxygen species, which are also by-products of the lipid peroxidation of unsaturated fatty acids (Ishii, et al., 2006). Malondialdehyde is also produced as a byproduct of the inactive thromboxane formation from its inactive form, inactive thromboxane TXA2, which is a vasoconstrictor agent (Bauer et al., 1999). This in turn supports our hypothesis about the lack of oxygen supply to the placental tissue on the one hand and the uterine tissue in the areas of growth and development of fetuses due to the lack of blood flow in them. On the other hand, a second byproduct of lipid peroxidation is the proliferation of smooth muscle cells of the lining of blood vessels that contribute to vascular injury (Watanabe et al., 2002). This results in early loss of embryos as well as impaired growth and development of embryos.

With regard to previous studies, it has been shown that oxidative stress is closely related to early miscarriage and many conditions related to pregnancy, which in turn occurs as a result of lack of oxygen in the uterine tissue during the early stages of pregnancy. Where the placenta are characterized by low antioxidant activity as 
well as their low concentrations, especially in the first trimester of pregnancy (Schoots et al., 2018). The blastocysts are more susceptive to damage resulting from variation in oxygen levels and free radicals resulting from the biological processes accompanying the implantation of embryos and their growth (Aouache et al., 2018; Mujica et al., 2018). The current study demonstrated that early exposure to oxidative stress in pregnant rats led to many undesirable effects, represented by a decrease in the number of blastocysts in the first week, an increase in the number of dead and absorbed embryos in the second week, and a decrease in the number of live embryos in the third week of pregnancy. The reason for these changes may be attributed to the enzymatic activity associated with the growth and development of the embryos and its increased influence on the metabolic processes in the placenta due to the imbalance of oxygen levels in the placental tissue, which results in an excessive increase in the synthesis and production of free radicals (Schoots et al., 2018). Whereas, it is known that placental hypoxia is closely related to the conversion of xanthine dehydrogenase into xanthine oxidase, the main source and important in generating cytotoxic free superoxide radicals (Poston et al., 2011). Burton et al. (2009) observed that lack of oxygen in the placental tissue causes stress of the endoplasmic reticulum stress and stimulates the formation and accumulation of misfolded proteins in the cell, leading to stimulation unfolded protein responses to try to restore the balance of the endoplasmic reticulum. This activity is mainly related to the functioning of placental cells in accordance with their levels of antioxidants and the level of oxygen in order to prevent tissue damage leading to premature death of the fetus or the inability of the uterine tissue to receive a fertilized egg (TorresCuevas et al., 2017).

\section{Conclusion}

Our study suggest that the desferal injection has a pro-oxidant capacity on rats' model at dose of $100 \mathrm{mg} / \mathrm{kg} \mathrm{BW}$. An oxidative stress plays an important role during pregnancy especially on prenatal development as well as persist up to postnatal life.

\section{Acknowledgement}

The authors express their deep thanks to the College of Veterinary Medicine for their approval of this work and the endless support of the head department of Physiology, Biochemistry and Pharmacology.

الإجهاد التأكسدي الناجم عن الديفيروكسامين (الديسفيرال) أثناء الحمل: دراسة قبل الولادة وبعدها

$$
\begin{aligned}
& \text { عبير أسماعيل ذنون , علي سعيد الجلبي } \\
& \text { فرع الفسلجة و الكيمياء الحياتية والأدوية, كلية الطب البيطري } \\
& \text { جامعة الموصل, الموصل , العراق }
\end{aligned}
$$

Email:alchalabi@uomosul.edu.iq

$$
\begin{aligned}
& \text { الخلاصة } \\
& \text { الهدف من الدراسة هو تقييم تأثير الإجهاد التأكسدي الناجم عن الديفيروكسامين (الديسفيرال) أثناء الحمل }
\end{aligned}
$$

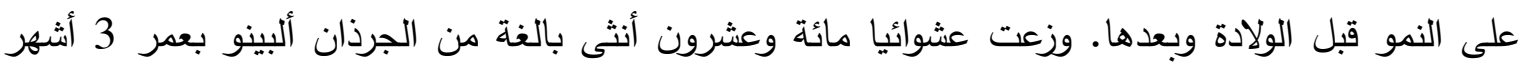


بمتوسط وزن 175-200 غم في مجموعتين رئيسيتين هما مجموعة السيطرة والتجربة (60 جرذ/ مجموعة). المجموعة الأولى (مجموعة السيطرة) تم حقنها بمحلول الملح الفسيولوجي 0,3 مل / حيوان ، والمجموعة الثانية تم حقنها بمحلول الديسفيرال بجرعة 100 ملغم / كغم وزن الجسم داخل الغشاء البريتوني (IP) مرة واحدة يومياً ولمدة ثلاثة أسابيع متتالية (أثناء فترة الحمل). عند نهاية المعاملة، تم تقسيم كل مجموعة بدورها إلى قسمين، كل قسم يضم 10 حيوانات، جمعت عينات الدم للتحليلات الكيموحيوية، ثم جمعت أنسجة الرحم والأجنة

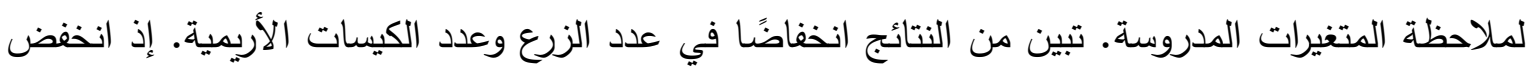
عدد الأجنة الحية بثكل ملحوظ مع زيادة عدد الأجنة الميتة والمعاد امتصاصها، وزيادة تشوه الأجنة في رحم مجموعة الإناث المجهدة مقارنة مع مجموعة السيطرة. ظهر من المشاهدات بعد الولادة اختلافات معنوية في

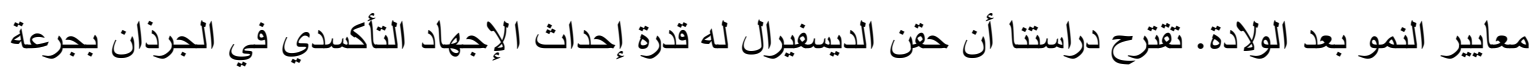

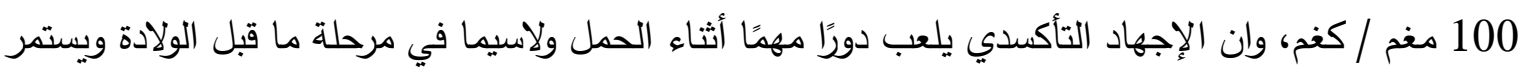
حتى بعد الولادة. الكلمات المفتاحية: ديسفيرال، الإجهاد التأكسدي ، تطورات قبل الولادة وبعدها. تاريخ تسلم البحث: 2020/12/15 ، وقبوله: 12/24/ 2021

\section{REFERENCES}

Agarwal, A., Aponte-Mellado, A., Premkumar, B. J., Shaman, A., and Gupta, S. (2012). The effects of oxidative stress on female reproduction: a review. Reproductive biology and endocrinology, 10(1), 1-31.

Agarwal, A., Gupta, S., and Sharma, R. K. (2005). Role of oxidative stress in female reproduction. Reproductive biology and endocrinology, 3(1), 1-21.

Al-Gubory, K. H., Fowler, P. A., and Garrel, C. (2010). The roles of cellular reactive oxygen species, oxidative stress and antioxidants in pregnancy outcomes. The international journal of biochemistry and cell biology, 42(10), 1634-1650.

Allen, P., Bennett, K., and Heritage, B. (2014). SPSS statistics version 22: A practical guide. Cengage Learning Australia.

Allen, R. G., and Tresini, M. (2000). Oxidative stress and gene regulation. Free Radical Biology and Medicine, 28(3), 463-499.

Amin, A., Gad, A., Salilew-Wondim, D., Prastowo, S., Held, E., Hoelker, M., and Tesfaye, D. (2014). Bovine embryo survival under oxidative-stress conditions is associated with activity of the NRF2-mediated oxidative-stress-response pathway. Molecular reproduction and development, 81(6), 497-513.

Aouache, R., Biquard, L., Vaiman, D., and Miralles, F. (2018). Oxidative stress in preeclampsia and placental diseases. International journal of molecular sciences, 19(5), 1496.

Balsinde, J., Winstead, M. V., and Dennis, E. A. (2002). Phospholipase A2 regulation of arachidonic acid mobilization. FEBS letters, 531(1), 2-6.

Bauer, J., Dau, C., Cavarape, A., Schaefer, F., Ehmke, H., and Parekh, N. (1999). ANG II-and TxA2-induced mesenteric vasoconstriction in rats is mediated by separate cell signaling pathways. American Journal of Physiology-Heart and Circulatory Physiology, 277(1), 1-7. 
Bertout, J., Mahutte, N. G., Preston, S. L., and Behrman, H. R. (2004). Reactive oxygen species and ovarian function. The ovary, 2, 353-368.

Brittenham, G. M. (2011). Iron-chelating therapy for transfusional iron overload. New England Journal of Medicine, 364(2), 146-156.

Buege, J. A., and Aust, S. D. (1978). Microsomal Lipid Peroxidation. In Methods in enzymology, 52: 302-310. Academic Press. https://doi.org/10.1016/S0076$\underline{6879(78) 52032-6}$

Burton, G. J., \& Jauniaux, E. (2011). Oxidative stress. Best practice \& research Clinical Obstetrics \& Gynaecology, 25(3), 287-299.

Duhig, Kate, Lucy C. Chappell, and Andrew H. Shennan. (2016). “Oxidative Stress in Pregnancy and Reproduction." Obstetric Medicine, 9(3):113-16.

Francisco, A.F., de Abreu Vieira, P.M., Arantes, J.M., Silva, M., Pedrosa, M.L., ElóiSantos, S.M., Martins-Filho, O.A., Teixeira-Carvalho, A., Araújo, M.S.S., Tafuri, W.L. and Carneiro, C.M. (2010). Increase of reactive oxygen species by desferrioxamine during experimental Changes' disease. Redox Report, 15(4), 185-190.

He, L., He, T., Farrar, S., Ji, L., Liu, T., and Ma, X. (2017). Antioxidants maintain cellular redox homeostasis by elimination of reactive oxygen species. Cellular Physiology and Biochemistry, 44(2), 532-553.

Hubel, C. A. (1999). Oxidative stress in the pathogenesis of preeclampsia. Proceedings of the Society for Experimental Biology and Medicine, 222(3), 222-235.

Ishii, T., Kumazawa, S., Sakurai, T., Nakayama, T., and Uchida, K. (2006). Mass spectroscopic characterization of protein modification by malondialdehyde. Chemical research in toxicology, 19(1), 122-129.

James, R. C., Goodman, D. R., and Harbison, R. D. (1982). Hepatic glutathione and hepatotoxicity: changes induced by selected narcotics. Journal of Pharmacology and Experimental Therapeutics, 221(3), 708-714.

Jiang, L., Chew, S. H., Nakamura, K., Ohara, Y., Akatsuka, S., andToyokuni, S. (2016). Dual preventive benefits of iron elimination by desferal in asbestosinduced mesothelial carcinogenesis. Cancer science, 107(7), 908-915.

Katsuki, H., Akino, N., Okuda, S., and Saito, H. (1995). Antioxidants, but not cAMP or high $\mathrm{K}+$; , prevent arachidonic acid toxicity on neuronal cultures. Neuroreport, 6(8), 1101-1104.

Kim, B. M., Choi, J. Y., Kim, Y. J., Woo, H. D., and Chung, H. W. (2007). Desferrioxamine (DFX) has genotoxic effects on cultured human lymphocytes and induces the p53-mediated damage response. Toxicology, 229(3), 226-235.

Lu, J., Wang, Z., Cao, J., Chen, Y., and Dong, Y. (2018). A novel and compact review on the role of oxidative stress in female reproduction. Reproductive Biology and Endocrinology, 16(1), 80.

Min, J., Park, B., Kim, Y. J., Lee, H., Ha, E., and Park, H. (2009). Effect of oxidative stress on birth sizes: consideration of window from mid pregnancy to delivery. Placenta, 30(5), 418-423.

Morehouse, K. M., Flitter, W. D., and Mason, R. P. (1987). The enzymatic oxidation of Desferal to a nitroxide free radical. FEBS letters, 222(2), 246-250.

Morehouse, K.M., W.D. Flitter and R.P. Mason. (1988). "The Enzymatic Oxidation 
of Desferal to a Nitroxide Free Radical. FEBS Letters 233(2):246-50.

Mujica, L. S., Bridi, A., Della Méa, R., Rissi, V. B., Guarda, N., Moresco, R. N., ... andComim, F. V. (2018). Oxidative stress and metabolic markers in pre-and postnatal polycystic ovary syndrome rat protocols. Journal of inflammation research, 11, 193.

Mukosera, G. T., Liu, T., Manaen, M., Zhu, L., Power, G., Schroeder, H., and Blood, A. B. (2020). Deferoxamine produces nitric oxide under ferricyanide oxidation, blood incubation, and UV-irradiation. Free Radical Biology and Medicine, 160, 458-470.

Mytilineou, C., Kramer, B. C., and Yabut, J. A. (2002). Glutathione depletion and oxidative stress. Parkinsonism and related disorders, 8(6), 385-387.

Nihara, Y., Ge, J., Shalev, O., Wu, H., Tu, A., and Tanaka, K. R. (2002). Desferrioxamine decreases NAD redox potential of intact red blood cells: evidence for desferrioxamine as an inducer of oxidant stress in red blood cells. BMC clinical pharmacology, 2(1), 1-4.

Palmer, C. W., and Post, K. (1995). Detection of sperm cells in the canine vagina. The Canadian Veterinary Journal, 36(5), 278.

Patil, S. B., Kodliwadmath, M. V., and Kodliwadmath, S. M. (2007). Study of oxidative stress and enzymatic antioxidants in normal pregnancy. Indian Journal of Clinical Biochemistry, 22(1), 135-137.

Pereira, A. C., and Martel, F. (2014). Oxidative stress in pregnancy and fertility pathologies. Cell biology and toxicology, 30(5), 301-312.

Poot, M., Rabinovitch, P. S., and Hoehn, H. (1989). Free radical mediated cytotoxicity of desferrioxamine. Free Radical Research Communications, 6(5), 323-328.

Poston, L., Igosheva, N., Mistry, H. D., Seed, P. T., Shennan, A. H., Rana, S., and Chappell, L. C. (2011). Role of oxidative stress and antioxidant supplementation in pregnancy disorders. The American journal of clinical nutrition, 94(suppl_6), 1980-1985.

Ruder, E. H., Hartman, T. J., and Goldman, M. B. (2009). Impact of oxidative stress on female fertility. Current Opinion in Obstetrics and Gynecology, 21(3), 219222

Schoots, M. H., Gordijn, S. J., Scherjon, S. A., van Goor, H., and Hillebrands, J. L. (2018). Oxidative stress in placental pathology. Placenta, 69, 153-161.

Sekhon, H., Gupta, L S., Kim, Y., and Agarwal, A. (2010). Female infertility and antioxidants. Current Women's Health Reviews, 6(2), 84-95.

Silveira, A. S., Aydos, R. D., Ramalho, R. T., Silva, I. S., Caldas, R. D. A., Santos Neto, A. T. D., and Rodrigues, C. T. (2018). Oxidative stress effects in the uterus, placenta and fetus of pregnant rats submitted to acute and chronic stress. Acta cirurgica brasileira, 33(9), 806-815.

Tada, M., Niwano, Y., and Kohno, M. (2015). Generation mechanism of Deferoxamine radical by tyrosine-tyrosinasereaction. Analytical Sciences, 31(9), 911-916.

Takamasa, Ishii, Masaki Miyazawa, YumiTakanashi, Maya Tanigawa, Kayo Yasuda, Hiromi Onouchi, Noboru Kawabe, JunjiMitsushita, Phil S. Hartman, and Naoaki Ishii. (2014). Genetically induced oxidative stress in mice causes 
thrombocytosis, splenomegaly and placental angiodysplasia that leads to recurrent abortion. Redox biology, 2, 679-685.

Torres-Cuevas, I., Parra-Llorca, A., Sánchez-Illana, A., Nuñez-Ramiro, A., Kuligowski, J., Cháfer-Pericás, C., and Vento, M. (2017). Oxygen and oxidative stress in the perinatal period. Redox biology, 12, 674-681.

Torres-Osorio, V., Urrego, R., Echeverri-Zuluaga, J. J., andLópez-Herrera, A. (2019). Oxidative stress and antioxidant use during in vitro mammal embryo production. Review. Revista mexicana de ciencias pecuarias, 10(2), 433-459.

Van Herck, H., Baumans, V., Brandt, C. J. W. M., Hesp, A. P. M., Sturkenboom, J. H., Van Lith, H. A., and Beynen, A. C. (1998). Orbital sinus blood sampling in rats as performed by different animal technicians: the influence of technique and expertise. Laboratory Animals, 32(4), 377-386.

Watanabe, T., Pakala, R., Katagiri, T., and Benedict, C. R. (2002). Oxidized lowdensity lipoproteins potentiate the mitogenic effect of 5-hydroxytryptamine on vascular smooth muscle cells. Japanese heart journal, 43(1), 35-42.

Wickens, D., Wilkins, M. H., Lunec, J., Ball, G., and Dormandy, T. L. (1981). Freeradical oxidation (peroxidation) products in plasma in normal and abnormal pregnancy. Annals of Clinical Biochemistry, 18(3), 158-162.

Wu, F., Tian, F., Zeng, W., Liu, X., Fan, J., Lin, Y., and Zhang, Y. (2017). Role of peroxiredoxin2 downregulation in recurrent miscarriage through regulation of trophoblast proliferation and apoptosis. Cell death and disease, 8(6), 2908.

$\mathrm{Yu}$, B. P. (1994). Cellular defenses against damage from reactive oxygen species. Physiological reviews, 74(1), 139-162. 